Elsevier

RSM 00001

Prelude

\title{
Risk management and good medicine
}

\author{
Graham Dukes
}

Key words: Risk management; History of medicine

There must have been a moment in everyone's life when he, or she, came to the conclusion that doctors were really rather special people. The impression may or may not have aroused emotion, and it may not even have persisted very long; but at that instant it was a clear, stark fact of life. For me, the date was November 2nd 1937, the time was approximately four in the afternoon. Why am I so sure? For one thing, because at that moment it entered my head that I might just go into medicine myself. For another, because it was my birthday, with lunch already deranged by small brother's otitis media, and teatime now promising to be upset by the advent of Dr William Ruckley with his hat, bag and stethoscope.

It was not at all the doctor himself, of blessed memory, who upset me, for he was wont to pat me on the head and call me Sunny Jim, which I thought privately was stupid but well intentioned. No, the upsetting thing was the ritual which started an hour in advance. The front door bell was polished; the floor in the hall on which $\mathrm{He}$ would tread was waxed; the maid scrubbed the washbasin in the bathroom three times and spent an unconscionable time arranging the soap and towel with which He would wash His hands; the family talked in hushed whispers as the hour approached when the Lanchester would drive up to the door and The Doctor would gravely emerge.

It had happened before and it would happen again, but that day stood out because of the Hat. The Doctor deposited his bowler hat on the chest in the hall before proceeding up to the bedroom, the family members placed strategically on the way to greet Him with due deference. What happened in the bedroom I never saw, but He had a way with small boys with otitis, or pneumonia or furuncles, unblest with M\& B 693 and penicillin though he may have been, and what he did was all skilful and caring and magic, and not solemn at all. It went so well on this occasion that, when The Doctor stepped over to the towel and soap, my small brother emerged much relieved from the bedroom, tripped down the stairs, and beheld the Hat. It was clearly not a proper hat, like the trilby which Father wore and which had a dent in it; it obviously needed denting; and so small brother lifted 
his small fist and dented it. The mortified family was, for the next few hours, as close to the proverbial sack and ashes as one would dare to get with a patient in the family. The good Doctor Ruckley, if I remember aright, was rather amused.

It is said that a doctor always remembers his first patient; it may be as true that a patient remembers his first doctor, and builds his image of the medical profession around him. My example was a good one, but it was also simple to perceive. What the family doctor of fifty years ago did, he did very largely with his own head, eyes and hands, and with simple, understandable tools, as many doctors in developing countries (and not only there) do today; he had the time to do his work well, and if he indeed did it caringly and skilfully, the result was often an evident matter, and a cause for his own rejoicing, as well as that of his patient. I do not imagine that $\mathrm{Dr}$ Ruckley would have known what risk management was; but it ran in his very veins.

This sort of memory is stirred by the type of paperback which, from time to time, sets out hysterically to alert and alarm the public as to the wickedness of doctors. Having put the medical profession on a quite unnecessary pedestal for several generations, the population is now periodically urged to cast it down and spit upon it. That is uncomfortable, unproductive and generally undeserved. There is surely no reason to think that doctors care any less about their patients than once they did, any more than there is reason to believe that railway signalmen have become less diligent or painters less talented than once they were. What has changed is the complexity of the scene in which the doctor works, and the degree of his dependence upon things only partly under his or her control. The technology which has enabled the doctor to achieve more is not simple to steer, and if it sometimes threatens to do harm as well as good, that may not be at all straightforward to assess, and the lessons may emerge only in a far future. As X-rays and acetylsalicylic acid approach their centenary, one is still learning how to use them safely and wisely; the havoc wrought by diethylstilbestrol in the offspring of pregnancies a lifetime ago may yet prove to extend to generations ahead. The more complicated medical techniques become, the more intricate their assessment; how long will it be before we truly know the ultimate prognosis of a modified transplantation technique or the safety of ultrasound for the foetus?

It takes effort and precious time to decide which questions we should be asking, and more to determine how we shall provide the most reliable answers to them. Yet the safe practice of medicine depends upon the patient and far-sighted recording and analysis of results, including resultant risk. That is a task for the individual, but also for the institution, the specialism and the profession, and in some situations also for industry and the public health authorities. From the findings one will commonly learn how risk can be contained and where there is a need for reparation.

The International Journal of Risk and Safety in Medicine takes precisely that for its province. Research must be the starting point, but there is a great deal of room for informed opinion and debate; for policy and patient care cannot afford to wait until we have all the facts in a row. Are we, with Tjeerd Tijmstra, concerned about the onslaught of the cholesterol measurers? How many of us have, like Sven Gisvold and his colleagues, found an effective way to measure our own performance in the profession? What can Europe learn from William Curran's thoughtful analysis of 
risk management in American medical care? Shall we adopt Harry Lambert's standards when we face the dilemma of drug testing in AIDS, those of Reidar Karlsen when we judge a device, and those of Tony Smith when we judge ourselves? How, with Petr Skrabanek's critical view before us, can we best approach quackery inside and outside medicine - if we know what we mean by it?

Those are not rhetorical questions; they are precisely the sort of questions which medicine needs to answer if it is to turn the technological revolution to its hand, rather than being swept up and swept away by it. To provide the answers one needs data, methods, good sense, and all of old Dr Ruckley's care for the patient. That is Risk Management in Medicine. This is its Journal. 